\title{
Comparative study of the functional outcomes of combined medial-lateral approach arthrolysis with or without external fixation for severe elbow stiffness
}

Dan Xiao ${ }^{\dagger}$, Maoqi Gong ${ }^{\dagger}$, Chen Chen, Yejun Zha, Ting Li, Shangwei Ji, Kehan Hua, Weitong Sun and Xieyuan Jiang*

\begin{abstract}
Background: To evaluate and compare the functional outcomes of combined medial-lateral approach open arthrolysis with and without hinged external fixation.

Methods: We retrospectively collected and analyzed the clinical data of patients with severe elbow stiffness who were treated in our institution from January 2018 to January 2019. All of them were treated with combined mediallateral approach arthrolysis. There were 20 patients who had the hinged external fixation placed and 29 patients without the placement of the external fixation. Their baseline characteristics and functional outcomes were evaluated and compared.

Results: The average follow-up time was $28.4 \pm 3.7$ months. There were no significant differences in the ROM of the elbow, MEPS, VAS, DASH, or complications between the two groups. The operation time and treatment cost of the patients without external fixation were significantly lower than patients with external fixation.
\end{abstract}

Conclusion: Combined medial-lateral approach open elbow arthrolysis without external fixation is a safe and effective way to treat elbow stiffness.

Level of evidence: Therapeutic Level III; Retrospective Cohort Comparison; Treatment Study.

Keywords: Elbow, Stiffness, Combined medial-lateral approach, Arthrolysis

\section{Background}

Elbow stiffness is defined as the compromised elbow function and motion due to traumatic or non-traumatic causes. Evidence showed that $12 \%$ of patients developed elbow stiffness after elbow injuries [1-3]. Morrey et al. [4] stated that the elbow functional range of motion (ROM) exceeding $30^{\circ}-130^{\circ}$ of extension-flexion and $50^{\circ}$

*Correspondence: jxy0845@sina.com

†Dan Xiao and Maoqi Gong contributed equally to this work. Department of Orthopedic Trauma, Beijing Jishuitan Hospital, No.31

Xinjiekou East Street, Xicheng District, Beijing 100035, China of pronation-supination is sufficient for daily activities. A loss of $50^{\circ}$ in the flexion-extension arc has been reported to cause an $80 \%$ loss of function [4]. Nowadays, due to the wide application of keyboards, mice and mobile phones, the ROM required by the elbow is larger than before [5]. Therefore, it is generally believed that the elbow stiffness can be diagnosed when the patient's elbow fails to accomplish daily activities due to the reduced ROM. Elbow stiffness can be divided into four degrees according to the extension-flexion arc: $\leq 30^{\circ}$ is extremely severe, $31^{\circ} \sim 60^{\circ}$ is severe, $61^{\circ} \sim 90^{\circ}$ is moderate, and $>90^{\circ}$ is mild [6]. original author(s) and the source, provide a link to the Creative Commons licence, and indicate if changes were made. The images or other third party material in this article are included in the article's Creative Commons licence, unless indicated otherwise in a credit line to the material. If material is not included in the article's Creative Commons licence and your intended use is not permitted by statutory regulation or exceeds the permitted use, you will need to obtain permission directly from the copyright holder. To view a copy of this licence, visit http://creativecommons.org/licenses/by/4.0/. The Creative Commons Public Domain Dedication waiver (http://creativeco mmons.org/publicdomain/zero/1.0/) applies to the data made available in this article, unless otherwise stated in a credit line to the data. 
Open arthrolysis is the most commonly used surgical method for elbow stiffness. For severe elbow stiffness (extension-flexion arc $\leq 60^{\circ}$ ), it is very difficult to achieve a complete restoration of ROM while preserving the stability of the elbow through the arthrolysis. Therefore, surgeons usually use hinged external fixation for several weeks to maintain the stability of the elbow after open arthrolysis. However, the application of hinged external fixation has many complications, including pin site infection, pin breakage, and radial nerve injury. It also lowers the postoperative quality of life and incurs high hospitalization expense [7-10]. Since 2018, our institution started to treat patients with severe elbow using the combined medial-lateral approach arthrolysis. This study aimed to compare the functional outcomes of the arthrolysis with and without hinged external fixation.

\section{Methods}

\section{Patients}

We retrospectively collected the data of patients with severe elbow stiffness at our institution between January 2018 and January 2019. We obtained institutional review board approval for this retrospective investigation, and informed consent was obtained from each patient. The inclusion criteria were (1) 18 to 60 years old; (2) severe elbow stiffness (extension-flexion arc $\leq 60^{\circ}$ ); and (3) treated by combined medial-lateral approach arthrolysis. The exclusion criteria were (1) concomitant burn or central nervous system injury; (2) elbows with rheumatoid arthritis or bone tumors; (3) follow-up time less than 2 years; or (4) incomplete clinical data.

A total of 128 patients underwent arthrolysis at our institution. After applying the inclusion and exclusion criteria, 49 patients were included in the study (Fig. 1), with a mean follow-up time of $28.4 \pm 3.7$ months (2435 months). We measured the ROM of the elbow [11]. To objectively evaluate the elbow function, the Mayo Elbow Performance Score (MEPS) was used with regard to 4 aspects: pain (45 points), ROM (20 points), stability (10 points), and the ability to accomplish daily activities ( 25 points) [12]. The Disabilities of the Arm, Shoulder and Hand (DASH) questionnaire was used to subjectively evaluate elbow-related symptoms and disability [13]. The decision of whether using the hinged external fixation was made according to the preferences of the surgeons and the patients' consent. The patients were then categorized into two groups: with hinged external fixation (group A) or without hinged external fixation (group B).

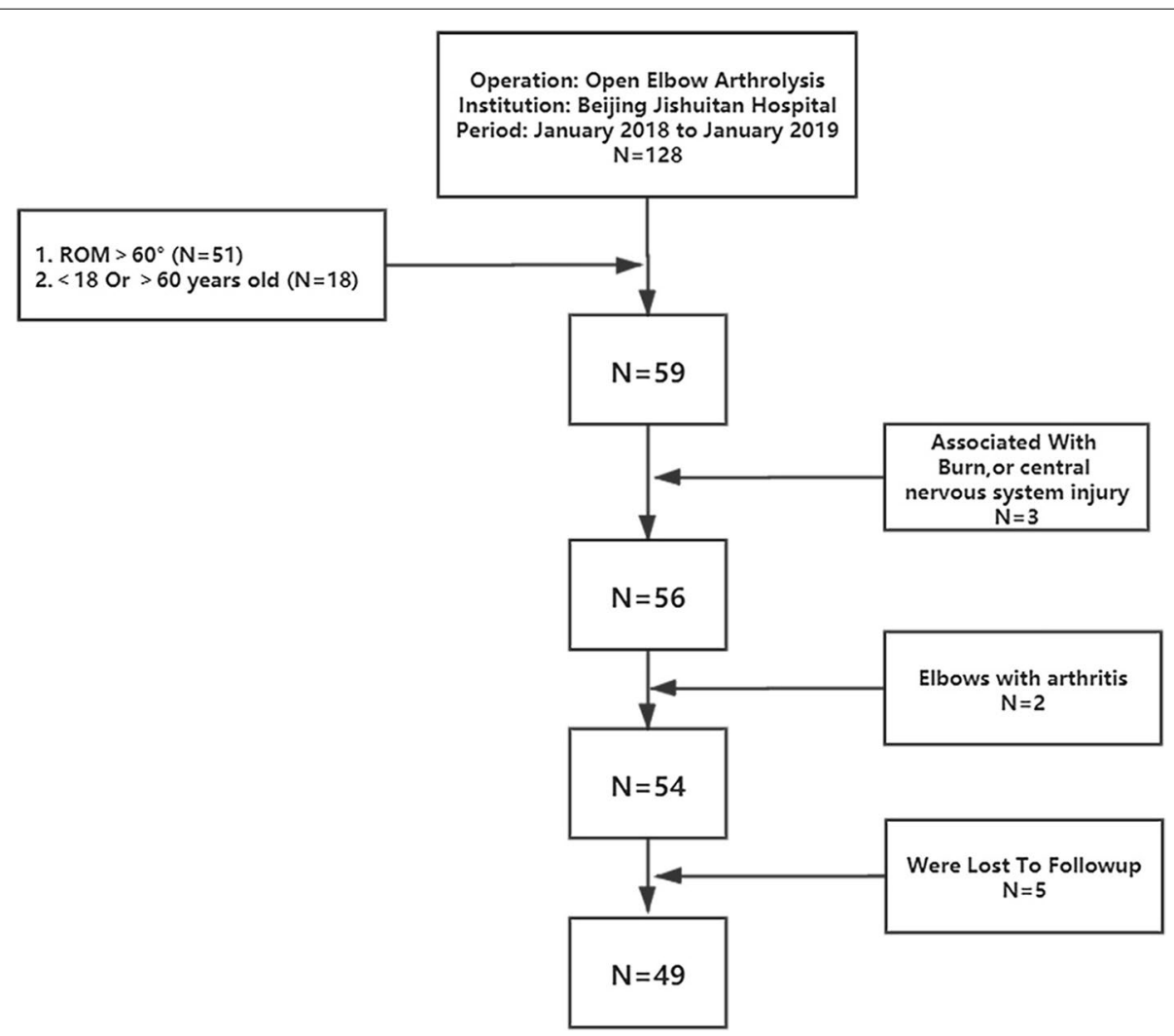

Fig. 1 The flowchart shows the inclusion and exclusion criteria 
All surgeries were performed by the same two surgeons, who were both well-trained and experienced in elbow arthrolysis. Group A consisted of 20 patients (16 males and 4 females), with an average age of $34.1 \pm 10.8$. Group B consisted of 29 patients (19 males and 10 females), with an average age of $37.6 \pm 11.2$ years. There were no significant differences in average age, sex, surgical side, body mass index (BMI) or incision type between the two groups (Table $1, P>0.05$ ). The original types of injury of patients in the two groups are shown in Table 1.

\section{Surgical technique}

Patients were placed in the standard supine position under general anesthesia or brachial plexus block. Sterile air tourniquets were applied.

A posterior midline incision or lateral and medial incisions were selected according to the previous surgical scar, location of heterotopic ossification (HO), and cause of stiffness. There was no significant difference in the choice of surgical incision between the two groups. $(\mathrm{P}>0.05$, Table 1$)$.

For the combined medial-lateral approach, the elbow was accessed medially first (Fig. 2). The ulnar nerve was exposed and protected. The triceps was reflected to the lateral side to exposed the medial and posterior aspect of the joint, and then the surgeons excised the $\mathrm{HO}$ on the posteromedial side of the joint, the posterior capsule and transverse and posterior bundle of the medial collateral ligament (MCL) while the anterior bundle was preserved. If there was still blockage posteriorly, the surgeons would perform olecranon fossa osteoplasty and olecranon tip excision in a consecutive manner.

On the lateral side, the lateral column procedure was done with partial extensor digitorum communis (EDC) split (Fig. 3) to expose the anterolateral part of the joint

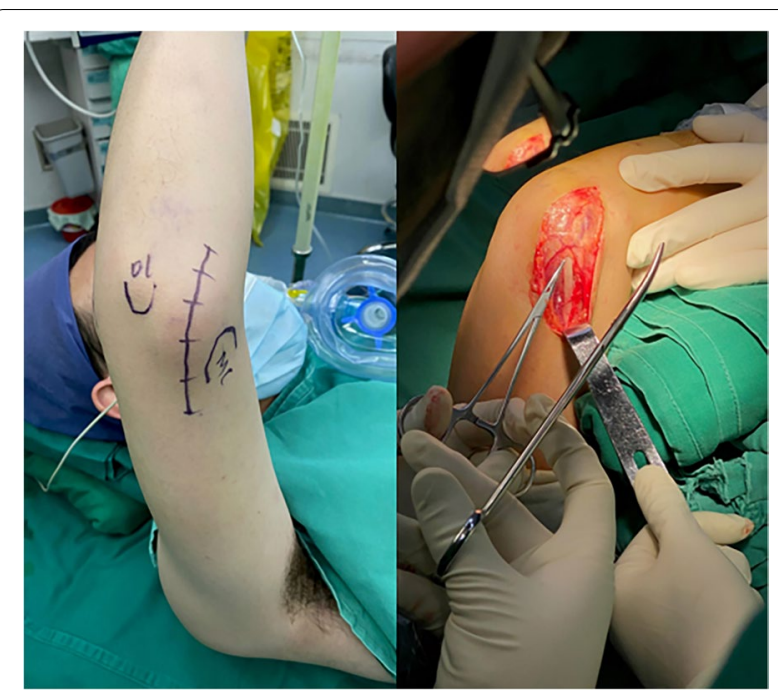

Fig. 2 The medial incision of combined medial-lateral approach arthrolysis

while preserving the lateral ulnar collateral ligament (LUCL). Surgeons then performed radial head fossa, coronoid fossa and coronoid process osteoplasty, and released the anterior capsule. If there was bony blockage on the posterolateral side, the surgeons would incise along the lateral margin of the triceps to expose the lateral ulnohumeral joint, excise the $\mathrm{HO}$ and release the posterolateral joint capsule.

The surgery was only considered complete when a satisfactory passive (moderate force) ROM was achieved under direct vision $\left(0^{\circ}-130^{\circ}\right.$ of extension-flexion. Figure 4). Lateral stress test and lateral pivot shift test were performed to assess elbow stability [14]. Then, the ulnar nerve was transposed anteriorly to reduce post-operative

Table 1 Comparison of the baseline characteristics between the two groups

\begin{tabular}{|c|c|c|c|c|}
\hline & & Group A (20) & Group B (29) & $P$ Value \\
\hline \multicolumn{2}{|l|}{ Age (Mean $\pm S D)$} & $34.1 \pm 10.8$ & $37.6 \pm 11.2$ & 0.272 \\
\hline \multicolumn{2}{|l|}{ Sex (male/female) } & $16 / 4$ & $19 / 10$ & 0.344 \\
\hline \multicolumn{2}{|l|}{ Side (left/right) } & $12 / 8$ & $11 / 18$ & 0.155 \\
\hline \multicolumn{2}{|l|}{ BMI } & $24.9 \pm 4.3$ & $24.8 \pm 4.6$ & 0.906 \\
\hline \multicolumn{2}{|c|}{ Incision (posterior midline/ lateral and medial) } & $17 / 12$ & $12 / 8$ & 1.000 \\
\hline \multirow{7}{*}{$\begin{array}{l}\text { The original injury types of } \\
\text { patients }\end{array}$} & Radial head fracture & 3 & 7 & \multirow[t]{7}{*}{0.564} \\
\hline & Olecranon fracture & 5 & 10 & \\
\hline & Distal humeral fracture & 7 & 8 & \\
\hline & Terrible triad of elbow & 2 & 2 & \\
\hline & Coronoid process fracture & 2 & 1 & \\
\hline & Elbow dislocation & 0 & 1 & \\
\hline & Prolonged immobilization & 2 & 0 & \\
\hline
\end{tabular}




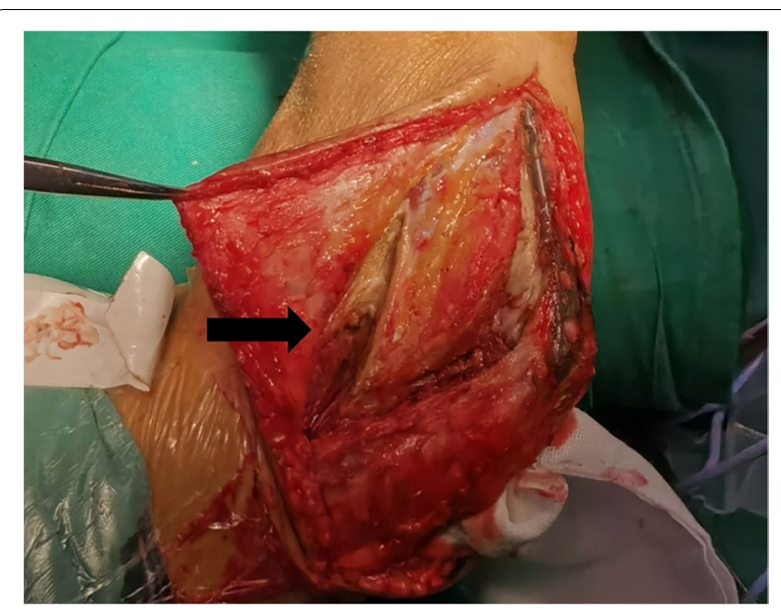

Fig. 3 The lateral column procedure with partial EDC split

ulnar nerve palsy. The fascia and subcutaneous tissue were closed layer by layer, and the incision was closed after the placement of drainage. Finally, a Stryker DJD II hinged external fixator was applied to the elbow based on the surgeon's preference and patient's consent.

\section{Postoperative treatment}

All patients received analgesia pumps for 3 days after surgery to alleviate postoperative pain and help postoperative exercise. Closed negative pressure drainage was left in place until the 24-h drainage volume was less than $30 \mathrm{ml}$. The patients received oral indomethacin $25 \mathrm{mg} /$ time, 3 times/day, for 6 weeks. On the second post-operative day, patients began to exercises by continuously flexing and extensing elbow and pronating and supinating the forearm with the assistance of the other arm. The external fixation was removed 6-8 weeks after surgery.

Patients were routinely followed up at 1, 3, 6 and 12 months postoperatively, and the last follow-up was performed for all patients 2 year after the operation. We measured the ROM of the elbow, MEPS, DASH, visual analogue scale (VAS) and documented the complications.
Postoperative standard anteroposterior and lateral X-rays of the elbows were taken, and examined to find the signs of joint degeneration and the evidence of newly formed HO (Fig. 5).

\section{Statistical analysis}

Statistical analyses were performed using SPSS software for Windows (IBM SPSS Statistics, version 24; IBM, Armonk, NY, USA). The changes in the ROM, VAS, MEPS and DASH in the same group were tested by paired t-tests. Then, the independent sample t-test was used to compare the perioperative data and improvement of functional outcome of patients between the two groups. The chi-square test was performed to compare the incidences of complications between groups. $P<0.05$ was considered statistically significant.

\section{Results}

Firstly, the ROM of patients in the two groups were compared before surgery and at the last follow-up (Table 2). The ROM and MEPS of all patients increased significantly after the surgery and rehabilitation compared to the pre-operative state $(P<0.05)$ while VAS and DASH scores decreased significantly $(P<0.05)$, indicating improvement of elbow function.

Subsequently, we made comparison of the perioperative data between the two groups (Table 3). There was no significant difference in hospitalization time $(P=0.069)$. The length of operation time and cost of treatment of group A were greater than those of group $\mathrm{B}(\mathrm{P}<0.05)$.

Then, we compared the degree of improvement in the functional outcome of patients between the two groups (Table 4). No significant difference was found between the two groups concerning the improvement of ROM, VAS, MEPS, or DASH (Table $4, P>0.05$ ). In group A, ulnar nerve symptoms were observed in 11 patients (55\%) post-operatively and 8 of which had completely recovered at the last follow-up. Elbow pain was observed in 4 patients $(20 \%)$ and all had relieved at the

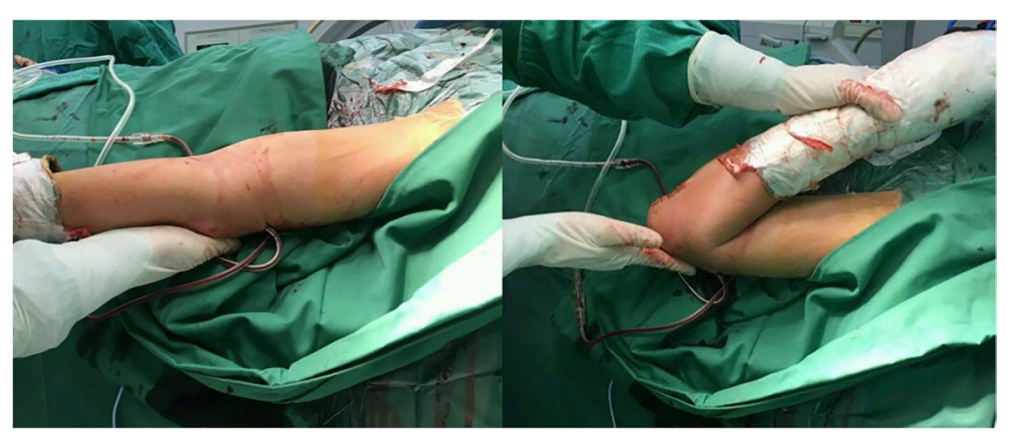

Fig. 4 The elbow was extended and flexed passively under direct vision after arthrolysis 


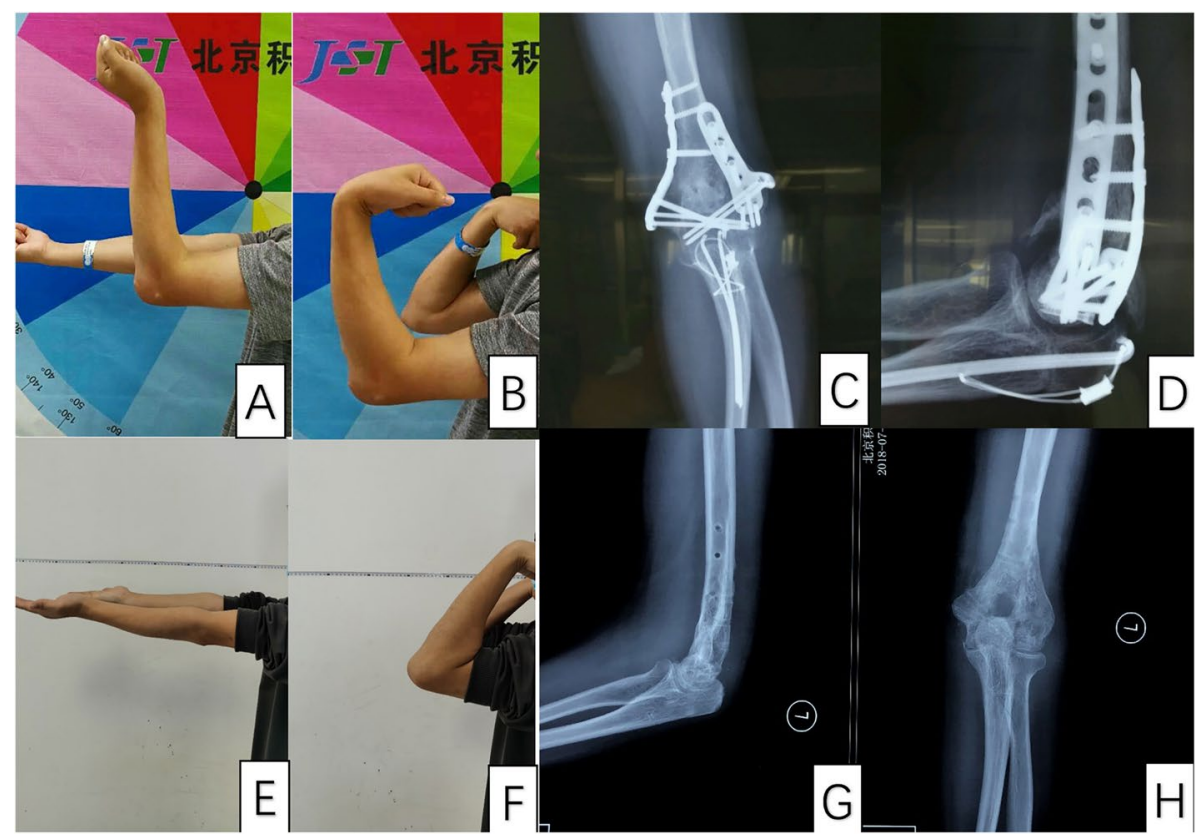

Fig. 5 Elbow function and X-ray preoperatively and postoperatively. (A and B) Preoperative extension and flexion. (C and D) Preoperative X-rays. (E and F) Extension and flexion at the last follow-up. ( $\mathrm{G}$ and $\mathrm{H}$ ) The X-rays at the last follow-up

Table 2 Comparison of the functional outcomes between pre-operation and the last follow-up

\begin{tabular}{lllllll}
\hline & & ROM of flexion and & ROM of rotation & VAS & MEPS & DASH \\
\hline Group A & pre-operation & $25.8 \pm 23.0$ & $106.5 \pm 52.8$ & $1.7 \pm 1.9$ & $58.3 \pm 15.7$ & $53.7 \pm 16.6$ \\
& the last follow-up & $132.1 \pm 15.8$ & $143.6 \pm 22.2$ & $0.3 \pm 0.5$ & $97.0 \pm 5.5$ & $6.5 \pm 4.8$ \\
& P & 0.000 & 0.001 & 0.007 & 0.000 & 0.000 \\
Group B & pre-operation & $26.7 \pm 21.8$ & $121.9 \pm 49.7$ & $2.6 \pm 2.1$ & $51.4 \pm 11.3$ & $46.7 \pm 15.0$ \\
& the last follow-up & $133.5 \pm 16.1$ & $140.1 \pm 21.2$ & $0.2 \pm 0.6$ & $96.4 \pm 6.1$ & $6.1 \pm 4.0$ \\
& P & 0.000 & 0.040 & 0.000 & 0.000 & 0.000 \\
\hline
\end{tabular}

Table 3 Comparison of the functional outcomes between the two groups

\begin{tabular}{llll}
\hline & Group A (20) & Group B (29) & P value \\
\hline Hospitalization time (days) & $11.6 \pm 3.9$ & $9.9 \pm 2.3$ & 0.069 \\
Operation time (minutes) & $155.1 \pm 60.7$ & $106.9 \pm 46.4$ & 0.003 \\
Intraoperative blood loss (ml) & $151.0 \pm 80.6$ & $89.3 \pm 55.7$ & 0.003 \\
Treatment cost (K yuan) & $54.7 \pm 15.9$ & $41.7 \pm 13.3$ & 0.003 \\
\hline
\end{tabular}

last follow-up. One patient (5\%) had recurrence of $\mathrm{HO}$ at the last follow-up. In group B, 15 patients $(51.7 \%)$ had ulnar nerve symptoms, and 13 patients had completely recovered at the last follow-up. Five patients (17.2\%) had elbow pain, all of whom were relieved at the last followup. Two patients (6.5\%) had recurrence of $\mathrm{HO}$ at the last follow-up. The recurrence of $\mathrm{HO}$ didn't affect the elbow functional outcomes of the three patients. There was no patient presented with surgical site infection or elbow instability. No significant difference concerning the rates of ulnar nerve symptoms $(P=1.000)$, pain $(P=0.320)$ and recurrence of $\mathrm{HO}(P=1.000)$ between the two groups was noticed (Table 5). In addition, there were 3 cases of pin site infection in group A before the removal of the external fixation and all of the pin tracts healed spontaneously after the removal of the pins.

\section{Discussion}

Open elbow arthrolysis is an effective treatment modality for elbow stiffness [15]. The restoration of the elbow function is mainly achieved through the excision of bony blockage, contracted joint capsule and scar tissue $[16,17]$. In the past, several studies reported the use of open arthrolysis in the treatment of elbow stiffness and 
Table 4 Comparison of the degree of improvement in the functional outcomes between the two groups

\begin{tabular}{lllll}
\hline & & Group A (20) & Group B (29) & P value \\
\hline Functional prognostic change & ROM of flexion and extension & $106.3 \pm 27.2$ & $106.8 \pm 27.0$ & $18.2 \pm 45.5$ \\
& ROM of rotation & $37.1 \pm 40.1$ & $-2.3 \pm 2.1$ & 0.942 \\
& VAS & $-1.4 \pm 2.0$ & $45.0 \pm 10.9$ & 0.140 \\
& MEPS & $38.8 \pm 17.3$ & $-40.6 \pm 13.8$ & 0.128 \\
\hline
\end{tabular}

provided the evidence that open arthrolysis could effectively improve elbow function and the quality of patients' life [18-22].

The important primary stabilizers of the elbow include the anterior bundle of the medial collateral ligament (aMCL), the LUCL (an important part of the lateral collateral ligament complex), and the congruence of the ulnohumeral joint [23-31].

In severe elbow stiffness, the soft tissue contracture and $\mathrm{HO}$ often contribute to the compromised elbow function. During the elbow release procedure, the aMCL and LUCL are often partially or completely damaged, resulting in instability of the elbow [32-34].

In order to avoid instability after arthrolysis, some surgeons use the technique of hinged external fixation. Zhou et al. [35] reported the functional outcome of 38 cases of open arthrolysis combined with external fixation (31 months of follow-up). The average ROM of flexion and extension arc increased from $27^{\circ}$ to $126^{\circ}$, and the ROM of rotation increased from $148^{\circ}$ to $153^{\circ}$. Sun et al. [36] reported the five-year follow-up results of 49 cases of open arthrolysis in combination with external fixation. The flexion-extension ROM increased from 27 degrees to $131^{\circ}$, and the average MEPS increased from 54 to 95; Kulkarni et al. [37] retrospectively analyzed 26 cases of open relaxation combined with external fixation (5.2 years of follow-up). The flexion-extension range improved by $102.4^{\circ}$, and the average MEPS increased by 44. In all these studies, the hinged external fixation provided stability for the elbow immediately after the surgery, which allowed safe and early exercise [38-40].

However, several studies also reported external fixation related complications such as pin tract infection, pin breakage, and radial nerve injury [36], as well as higher hospitalization costs and longer operation times [7-10]. Ring et al. [41] retrospectively compared the prognosis of patients with elbow stiffness who underwent elbow release with external fixation (23 cases) or without external fixation (19 cases). The changes in ROM of the two groups showed no statistical significant difference $\left(89^{\circ}\right.$ VS $\left.78^{\circ}, \mathrm{P}>0.05\right)$. In the external fixation group, 5 patients developed pin loosening and infection, 1 patient had ulnar fracture, and 2 patients had pin breakage.

For patients with severe stiffness, completely removing the $\mathrm{HO}$ and soft-tissue contracture of the elbow while preserving the aMCL and LUCL is still a fair challenge. To solve this problem, our institution modified the traditional elbow arthrolysis procedure. In previous studies, the anterior part of the joint were often released through the medial over-the-top approach [22, 42], which inevitably damages the aMCL. On the lateral side, the anterolateral joint was accessed through extended Kocher approach [19, 43, 44], which would often damage the LUCL. The damage to the aMCL or LUCL would compromise the stability of the elbow. In our study, we used the combined medial-lateral approach. Our procedure on the medial side focused on the release of the posterior joint capsule, while protecting the aMCL. On the lateral side, the lateral column procedure was performed with partial EDC split instead of Kocher approach. Therefore, the LUCL always remains intact. After the excision of $\mathrm{HO}$ and soft-tissue contracture, the lateral stress test and lateral pivot shift test were performed to evaluate the elbow stability, and none of the patients in our study showed immediate elbow instability.

The decision of whether using the hinged external fixation was made according to the preferences of the surgeons and the patients' consent. Although the stability of

Table 5 Comparison of the complications between the two groups

\begin{tabular}{lllll}
\hline & & Group A (20) & Group B (29) & P value \\
\hline Compli-cations & Ulnar nerve symptoms (finally) & $3(15 \%)$ & $2(6.9 \%)$ & 1.000 \\
& Elbow pain & $4(20 \%)$ & $5(17.2 \%)$ & 0.320 \\
& Recurrence of HO & $1(5 \%)$ & $2(6.9 \%)$ & 1.000 \\
& Pin site infection & 3 & - & - \\
\hline
\end{tabular}


the elbow was confirmed intra-operatively, some surgeons still preferred to use an external fixator after arthrolysis in order to avoid instability of the elbow during early stage rehabilitation. While other surgeons thought the use of external fixation was not necessary for early rehabilitation. In addition, surgeons would tell the patients the pros and cons about the external fixation before operation, and some patients refused to accept the use of it because of the inconvenience and the increased treatment cost. This study compared the functional results of the two groups of patients with or without external fixation after combined mediallateral approach arthrolysis in our hospital. Compared with preoperative data, the flexion and extension ROM, rotational ROM, MEPS, VAS, and DASH were significantly improved $(\mathrm{P}<0.05)$, suggesting that both methods could achieve satisfactory functional outcomes of these patients.

Furthermore, we compared the functional result between patients with and without the external fixation. There were no statistically significant difference in the ROM, MEPS, DASH, VAS (P>0.05). Additionally, the operation time and the cost of the patients without external fixation were significantly lower than those with external fixation. Pin tract infection was found in three patients who received the external fixation. These results confirmed that for patients with severe elbow stiffness, the use of combined medial-lateral approach arthrolysis without external fixation could improve the functional outcomes of elbows and was relatively safe.

This study has the following limitations: (1) as a retrospective study, the result is prone to have selection bias; (2) the size of this study, though comparable to or even larger than similar studies, may not be large enough to show the difference between groups; (3) the measurement of ROM of elbows was performed by the same doctor, and there may have been favour detection bias; and (4) the surgeries were performed by two surgeons, and there may have been bias to the surgical outcomes.

\section{Conclusion}

The use of combined medial-lateral approach open elbow arthrolysis to treat severe elbow stiffness significantly improves the ROM and function of the elbow. The stability of the elbows can be achieved without external fixation. Not using the external fixation spares patients the complications and inconvenience of external fixation. Furthermore, the use of external fixation lengthens hospitalization cost and increases the operation time.

\section{Abbreviations}

ROM: Range of motion; MEPS: The Mayo Elbow Performance Score; DASH: The Disabilities of the Arm, Shoulder and Hand; BMI: Body mass index; HO: Heterotopic ossification; MCL: The medial collateral ligament; EDC: Extensor digitorum communis; LUCL: The lateral ulnar collateral ligament; VAS: Visual analogue scale; aMCL: The anterior bundle of the medial collateral ligament.

\section{Acknowledgements}

Not applicable.

\section{Authors' contributions}

All listed authors made significant contributions to this manuscript. XD and GMQ wrote the manuscript, CC and ZYJ performed surgeries, GMQ, LT and SWT collected the follow-up data, XD, JSW and HKH performed statistical analysis and data management, JXY initiated the study, JXY, GMQ, CC were major contributor in the revision of this manuscript. All authors read and approved the final manuscript.

\section{Funding}

1. Funder: Beijing Municipal Health Commission

Grant name (number): Beijing Municipal Health Commission (BMHC2019-9). 2. Funder: Beijing Natural Science Foundation

Grant name (number): Beijing Natural Science Foundation (L192049).

3. Funder: Beijing Jishuitan Hospital

Grant name (number): Beijing Jishuitan Hospital Nova Program (XKXX202103)

\section{Availability of data and materials}

The datasets generated and/or analysed during the current study are not publicly available due to limitations of ethical approval involving the patient data and anonymity but are available from the corresponding author on reasonable request.

\section{Declarations}

Ethics approval and consent to participate

This study had been approved by Institutional Review Board (IRB) of Beijing Jishuitan Hospital (JST202012-06), and all methods were performed in accordance with the relevant guidelines and regulations. Informed consent was obtained from each patient.

\section{Consent for publication}

We confirmed that the written consent to publish this manuscript was obtained from the study participant.

\section{Competing interests}

The authors declare that they have no competing interests.

Received: 3 June 2021 Accepted: 12 October 2021

Published online: 10 November 2021

References

1. Charalambous CP, Morrey BF. Posttraumatic elbow stiffness. J Bone Joint Surg Am. 2012;94:1428-37. https://doi.org/10.2106/JBJS.K.00711.

2. Dávila SA, Johnston-Jones K. Managing the stiff elbow: operative, nonoperative, and postoperative techniques. J Hand Ther. 2006;19:268-81. https://doi.org/10.1197/j.jht.2006.02.017.

3. Myden C, Hildebrand K. Elbow joint contracture after traumatic injury. J Shoulder Elb Surg. 2011;20:39-44. https://doi.org/10.1016/j.jse.2010.07.013.

4. Morrey BF, Askew LJ, Chao EY. A biomechanical study of normal functional elbow motion. J Bone Joint Surg Am. 1981;63:872-7.

5. Sardelli M, Tashjian RZ, MacWilliams BA. Functional elbow range of motion for contemporary tasks. J Bone Joint Surg Am. 2011;93:471-7. https://doi.org/10.2106/JBJS.I.01633.

6. Morrey BF. The posttraumatic stiff elbow. Clin Orthop Relat Res. 2005:2635. https://doi.org/10.1097/01.blo.0000152366.58660.ea.

7. Cai J, Wang W, Yan H, Sun Y, Chen W, Chen S, et al. Complications of open elbow Arthrolysis in post-traumatic elbow stiffness: a systematic review. PLoS One. 2015;10:e0138547. https://doi.org/10.1371/journal. pone. 0138547 .

8. Cheung EV, O'Driscoll SW, Morrey BF. Complications of hinged external fixators of the elbow. J Shoulder Elb Surg. 2008;17:447-53. https://doi. org/10.1016/j.jse.2007.10.006. 
9. Iordens Gl, Den Hartog D, Van Lieshout EM, Tuinebreijer WE, De Haan J, Patka P, et al. Good functional recovery of complex elbow dislocations treated with hinged external fixation: a multicenter prospective study. Clin Orthop Relat Res. 2015;473:1451-61. https://doi.org/10.1007/ s11999-014-3959-1.

10. Ring D, Bruinsma WE, Jupiter JB. Complications of hinged external fixation compared with cross-pinning of the elbow for acute and subacute instability. Clin Orthop Relat Res. 2014;472:2044-8. https://doi.org/10. 1007/s11999-014-3510-4.

11. Zdravkovic V, Jost B. Rounded data have a high potential for false comparative statistical results as shown with elbow arc of motion. J Shoulder Elb Surg. 2018;27:276-81. https://doi.org/10.1016/j.jse.2017.10.033.

12. Cusick MC, Bonnaig NS, Azar FM, Mauck BM, Smith RA, Throckmorton TW. Accuracy and reliability of the Mayo elbow performance score. J Hand Surg Am. 2014:39:1146-50. https://doi.org/10.1016/j.jhsa.2014.01.041.

13. Hudak PL, Amadio PC, Bombardier C. Development of an upper extremity outcome measure: the DASH (disabilities of the arm, shoulder and hand) [corrected]. The upper extremity collaborative group (UECG). Am J Ind Med. 1996;29:602-8. https://doi.org/10.1002/(SICI)1097-0274(199606) 29:63.0.CO;2-L.

14. Hsu SH, Moen TC, Levine WN, Ahmad CS. Physical examination of the athlete's elbow. Am J Sports Med. 2012;40:699-708. https://doi.org/10. 1177/0363546511428869

15. Pettersen PM, Eriksson J, Bratberg H, Myrseth LE, Bjørnstad LG, Johansen $M$, et al. Increased ROM and high patient satisfaction after open arthrolysis: a follow-up-study of 43 patients with posttraumatic stiff elbows. BMC Musculoskelet Disord. 2016;17:74. https://doi.org/10.1186/ s12891-016-0928-8.

16. Lindenhovius AL, Linzel DS, Doornberg JN, Ring DC, Jupiter JB. Comparison of elbow contracture release in elbows with and without heterotopic ossification restricting motion. J Shoulder Elb Surg. 2007;16:621-5. https://doi.org/10.1016/j.jse.2007.01.005.

17. Yu SY, Wang W, Liu S, Ruan HJ, Liu JJ, Li XJ, et al. Arthrolysis and delayed internal fixation combined with hinged external fixation for elbow stiffness associated with malunion or nonunion of capitellum fracture. $J$ Shoulder Elb Surg. 2015;24:941-6. https://doi.org/10.1016/j.jse.2015.01. 019.

18. Birjandi Nejad A, Ebrahimzadeh MH, Moradi A. Clinical outcomes after posterior open elbow arthrolysis for posttraumatic elbow stiffness. Arch Trauma Res. 2014;3:e21742. https://doi.org/10.5812/atr.21742.

19. Haglin JM, Kugelman DN, Christiano A, Konda SR, Paksima N, Egol KA. Open surgical elbow contracture release after trauma: results and recommendations. J Shoulder Elb Surg. 2018;27:418-26. https://doi.org/10. 1016/j.jse.2017.10.023

20. Kodde IF, van Rijn J, van den Bekerom MP, Eygendaal D. Surgical treatment of post-traumatic elbow stiffness: a systematic review. J Shoulder Elb Surg. 2013;22:574-80. https://doi.org/10.1016/j.jse.2012.11.010.

21. Koh KH, Lim TK, Lee HI, Park MJ. Surgical treatment of elbow stiffness caused by post-traumatic heterotopic ossification. J Shoulder Elb Surg. 2013;22:1128-34. https://doi.org/10.1016/j.jse.2013.04.019.

22. Tan V, Daluiski A, Simic P, Hotchkiss RN. Outcome of open release for post-traumatic elbow stiffness. J Trauma. 2006;61:673-8. https://doi.org/ 10.1097/01.ta.0000196000.96056.51.

23. Morrey BF, An KN. Articular and ligamentous contributions to the stability of the elbow joint. Am J Sports Med. 1983;11:315-9. https://doi.org/10. 1177/036354658301100506.

24. Podgórski AP, Kordasiewicz B, Pomianowski S. The column procedure preserves elbow stability on biomechanical testing. Int Orthop. 2020;44:9118. https://doi.org/10.1007/s00264-020-04494-0.

25. Safran MR, Baillargeon D. Soft-tissue stabilizers of the elbow. J Shoulder Elb Surg. 2005;14:179S-85S. https://doi.org/10.1016/j.jse.2004.09.032.

26. Ciccotti MC, Hammoud S, Dodson CC, Cohen SB, Nazarian LN, Ciccotti MG. Stress ultrasound evaluation of medial elbow instability in a cadaveric model. Am J Sports Med. 2014:42:2463-9. https://doi.org/10.1177/ 0363546514542805.
27. Eygendaal D, Olsen BS, Jensen SL, Seki A, Söjbjerg JO. Kinematics of partial and total ruptures of the medial collateral ligament of the elbow. J Shoulder Elb Surg. 1999;8:612-6. https://doi.org/10.1016/s1058-2746(99) 90099-x.

28. Seiber K, Gupta R, McGarry MH, Safran MR, Lee TQ. The role of the elbow musculature, forearm rotation, and elbow flexion in elbow stability: an in vitro study. J Shoulder Elb Surg. 2009;18:260-8. https://doi.org/10. 1016/j.jse.2008.08.004.

29. Søjbjerg JO, Ovesen J, Nielsen S. Experimental elbow instability after transection of the medial collateral ligament. Clin Orthop Relat Res. 1987:186-90. https://doi.org/10.1097/00003086-198705000-00026.

30. Werner FW, An KN. Biomechanics of the elbow and forearm. Hand Clin. 1994;10:357-73.

31. O'Driscoll SW, Bell DF, Morrey BF. Posterolateral rotatory instability of the elbow. J Bone Joint Surg Am. 1991;73:440-6.

32. Kayalar M, Ozerkan F, Bal E, Toros T, Ademoğlu Y, Ada S. Elbow arthrolysis in severely stiffe elbows. Arch Orthop Trauma Surg. 2008;128:1055-63. https://doi.org/10.1007/s00402-008-0626-6.

33. Ring D, Jupiter JB. Operative release of ankylosis of the elbow due to heterotopic ossification. Surgical technique. J Bone Joint Surg Am. 2004;86-A Suppl 1:2-10. https://doi.org/10.2106/00004623-200403001-00002.

34. Wang W, Jiang SC, Liu S, Ruan HJ, Fan CY. Stability of severely stiff elbows after complete open release: treatment by ligament repair with suture anchors and hinged external fixator. J Shoulder Elb Surg. 2014;23:153744. https://doi.org/10.1016/j.jse.2014.03.013.

35. Zhou Y, Cai JY, Chen S, Liu S, Wang W, Fan CY. Application of distal radiuspositioned hinged external fixator in complete open release for severe elbow stiffness. J Shoulder Elb Surg. 2017;26:e44-44e51. https://doi.org/ 10.1016/j.jse.2016.09.019.

36. Sun Z, Cui H, Ruan J, Li J, Wang W, Fan C. What range of motion and functional results can be expected after open Arthrolysis with hinged external fixation for severe posttraumatic elbow stiffness. Clin Orthop Relat Res. 2019;477:2319-28. https://doi.org/10.1097/CORR.00000000000000726.

37. Kulkarni GS, Kulkarni VS, Shyam AK, Kulkarni RM, Kulkarni MG, Nayak P. Management of severe extra-articular contracture of the elbow by open arthrolysis and a monolateral hinged external fixator. J Bone Joint Surg Br. 2010;92:92-7. https://doi.org/10.1302/0301-620X.92B1.22241.

38. Bauer AS, Lawson BK, Bliss RL, Dyer GS. Risk factors for posttraumatic heterotopic ossification of the elbow: case-control study. J Hand Surg Am. 2012;37:1422-9.e1-6. https://doi.org/10.1016/j.jhsa.2012.03.013.

39. Morrey BF, An KN. Stability of the elbow: osseous constraints. J Shoulder Elb Surg. 2005;14:174S-8S. https://doi.org/10.1016/j.jse.2004.09.031.

40. Wang W, Liu S, Jiang SC, Ruan HJ, He N, Fan CY. Limited medial and lateral approaches to treat stiff elbows. Orthopedics. 2015;38:e477-84. https:// doi.org/10.3928/01477447-20150603-55.

41. Ring D, Hotchkiss RN, Guss D, Jupiter JB. Hinged elbow external fixation for severe elbow contracture. J Bone Joint Surg Am. 2005;87:1293-6. https://doi.org/10.2106/JBJS.D.02462.

42. Piper SL, Lattanza LL, Shen TS, Wall LB, Goldfarb CA. Open surgical release of posttraumatic elbow contracture in children and adolescents. J Pediatr Orthop. 2019;39:241-6. https://doi.org/10.1097/BPO.0000000000000923.

43. Liu S, Fan CY, Ruan HJ, Li FF, Tian J. Combination of arthrolysis by lateral and medial approaches and hinged external fixation in the treatment of stiff elbow. J Trauma. 2011;70:373-6. https://doi.org/10.1097/TA.0b013 e3181e4f5e3.

44. Ruan HJ, Liu S, Fan CY, Liu JJ. Open arthrolysis and hinged external fixation for posttraumatic ankylosed elbows. Arch Orthop Trauma Surg. 2013;133:179-85. https://doi.org/10.1007/s00402-012-1659-4.

\section{Publisher's Note}

Springer Nature remains neutral with regard to jurisdictional claims in published maps and institutional affiliations. 